\title{
AMISTAD E IDENTIDAD: LAS POETAS ESPAÑOLAS DE LOS AÑOS 20
}

\author{
Rosa Fernández Urtasun \\ Universidad de Navarra \\ rosafu@unav.es
}

\section{RESUMEN}

A finales de los años 20 las mujeres españolas que buscaban abrirse paso en el mundo de la poesía crearon una serie de vínculos que se disolvieron con la llegada de la guerra civil. Hasta ahora apenas se ha subrayado esta característica por la fuerte ruptura que supuso para ellas la guerra civil y la experiencia del exilio. Para recuperar la vivencia de unidad que de hecho se produjo en aquellos años es necesario acudir a los testimonios contemporáneos. La publicación de fondos epistolares y documentación sobre las poetas de los años 20 y 30 permite hacer una aproximación adecuada a este fenómeno. De estos materiales me he servido para arrojar una nueva luz sobre el desarrollo de la literatura femenina en España.

PALABRAS ClAVE: mujeres, poesía, años 20, epistolarios, amistad.

\section{Abstract}

At the end of the 20's, those Spanish women who wanted to break into the world of poetry created a series of relationships that were broken with the arrival of the civil war. So far this has been very little emphasized due to the sharp break created by the civil war and the experience of exile. To recover the experience of unity that actually occurred in those years, it is necessary to go back to contemporary accounts. The release of archives and epistolary of women poets of the 20's and 30's allows a proper approach to this 
phenomenon. Those materials I have used to shed a new light on the development of women's literature in Spain.

KEY WORDS: women, poetry, 20's, epistolary, friendship.

Durante la década de los años 20 la poesía española logró un impulso y una calidad que no había alcanzado desde los comienzos de la modernidad. Se conformó entonces un grupo de escritores a quienes se conoce habitualmente como «generación del 27». Esta denominación se toma del homenaje que hicieron a Góngora, no por el papel del cordobés como precursor o maestro, sino porque en ese acto los participantes definieron su identidad colectiva como grupo de poetas con intereses comunes.

En los relatos que dan testimonio del desarrollo de este acontecimiento no se nombra a ninguna mujer, ya que entonces era impensable que ellas pudieran participar en un homenaje intelectual. Sin embargo, en esas mismas fechas se estaba formando por primera vez en la literatura española un núcleo de mujeres que querían hacer de la poesía una tarea principal. En distintas ocasiones se ha marcado el año de 1926 como momento clave en el desarrollo de la poesía femenina española contemporánea (Mainer 19-20, Miró 20). Ese año ven la luz poemarios como Inquietudes. Poemas, de Concha Méndez Cuesta y En silencio..., de Ernestina de Champourcin, y se funda el Lyceum Club. Muy poco antes se habían publicado Sembrad, de Cristina de Arteaga (1925) y Poesías (1923), de María Teresa Roca de Togores. Ernestina de Champourcin recuerda, con una frase sucinta y significativa, que la primera reacción en los círculos literarios ante esta inusitada muestra de poesía femenina fue de desconfianza: «aquellos libros no podían ser nuestros: éramos mujeres» $(1997,23)$. Esta desconfianza se debía interpretar como una señal de calidad de las obras, que no buscaban un puesto decorativo en los suplementos femeninos de las revistas sino ser tratadas en términos de igualdad con las del resto de sus colegas masculinos.

De manera aún más radical que los poetas de «la generación del 27», estas escritoras consiguieron, gracias a su amistad, impulsarse mutuamente para poder salir a la esfera pública. Nieva de la Paz, al estudiar las memorias que algunas de estas mujeres escribieron hacia el final de su vida, confirma que «las amistades literarias entre escritoras fueron claves en un periodo todavía muy difícil para la inserción de las mujeres en la profesión» $(2006,22)^{1}$.

Sin embargo, hasta ahora no se ha hecho apenas referencia a esta cualidad de grupo en los estudios sobre las mujeres que escribían en los años 20, quizá porque ni siquiera ellas mismas lo hacen al escribir sus memorias. Esto es, sin embargo, habitual en casos paralelos. Como explica Hazlett (3-4), mientras la conciencia de identidad grupal suele situarse en los años de adolescencia y primera juventud, hacia el final de la vida los caminos se dividen y la identidad personal se reafirma, de tal modo que la conciencia de grupo muchas veces se olvida o voluntariamente se relega a un plano secundario.

\footnotetext{
${ }^{1}$ Stanton afirma que «more than the ambiguous inscription of multiple personal relations, the autogynographical narrative was marked by conflicts between the private and the public, the personal and the professional. As F. S. observed, there was a systematic tension between the conventional role of wife, mother, or daughter and another, unconventional self that had ambition or a vocation» (13).
} 
En efecto, también en la vida de estas mujeres se verifica una larga distancia entre la época de su iniciación a la escritura, en la que se configuran estas relaciones de amistad, y el momento en el que escriben las memorias. A esto hay que sumar la fuerte quiebra que supuso la guerra civil, junto con el éxodo y dispersión que se produjeron tras ella. Era lógico que se rompieran los vínculos que se habían ido formando desde finales de los años 20 en el ámbito de la poesía femenina. Sin embargo, hoy es posible recuperar la vivencia de unidad que de hecho se produjo en aquellos años acudiendo a los testimonios contemporáneos, que podemos encontrar rastreando los epistolarios y archivos. Esto es lo que propongo revisar en este trabajo.

El contexto histórico y social en el que se movía estas mujeres se conoce cada vez mejor ${ }^{2}$. Las jóvenes citadas más arriba, con la excepción de Concha Méndez, pertenecían a una clase social alta. Eran aristócratas, y habían recibido una educación esmerada. En este ambiente publicar un libro de poemas se entendía como un capricho propio de señoritas, pero ni siquiera se consideraba la posibilidad de que fuera el comienzo de una carrera literaria. Autoras como M. ${ }^{\mathrm{a}}$ Teresa Roca de Togores o Cristina de Arteaga consideraban la poesía como una ocupación culta, interesante y enriquecedora, pero de carácter secundario.

Sin embargo, otras consideraban que la mujer tenía que empezar a jugar un papel relevante dentro del mundo de la cultura. Ernestina de Champourcin, por ejemplo, no ve en la poesía como una afición pasajera, sino que comprende la escritura como aquello que la define de manera esencial. Y va a empeñarse en que esa percepción individual alcance una dimensión social: exige un reconocimiento exterior. De ahí que desde muy joven decida enviar sus poemas a diferentes revistas: Manantial, Vida Aristocrática, Cartagena Ilustrada, La Libertad. La positiva acogida de sus versos le impulsa a publicar su primer libro, En silencio..., a pesar de que sabía que en su ambiente sería recibido con más de una burla. Con el paso de los años, reflejaba así el rechazo que suscitó a su alrededor:

Mi primer libro en el 26. Mal efecto entre las amistades. Bachillera fue uno de los calificativos que me otorgaron. Hacía tiempo que me sentía distinta, sensación muy desagradable, aunque muchas personas piensen lo contrario. Desde mi amor por los libros me sentía diferente. Era muy molesto, pero después de publicar En silencio la cosa aumentó. No se me olvida el comentario del muchacho que en una reunión de gente joven me espetó de pronto: no juegas al bridge, no bailas, entonces, ¿para qué sirves? (Antón 252)

En este breve fragmento encontramos, desde el primer momento, el contraste entre la afirmación de su identidad como poeta y el mundo que le rodea. Sus pretensiones literarias se interpretaban como una incursión indebida en un campo que era exclusivamente masculino y como una falta de adecuación a las convenciones sociales exigidas para una mujer aristócrata.

De hecho, Ernestina había ya comenzado a frecuentar los entornos intelectuales, muy marcados en la época por tendencias ideológicas republicanas y liberales. En estos momentos se vuelca hacia publicaciones de mayor prestigio, como La Gaceta Literaria, El Heraldo o El Sol, donde comienza a publicar poemas y reseñas críticas. Muy pronto,

\footnotetext{
${ }^{2}$ Por citar algunos ejemplos, puede ser interesante contrastar los trabajos de Quiles Faz (con testimonios contemporáneos de la periodista Isabel Oyarzabal), Castillo-Martín (quien muestra el ambiente social que rodeaba a las mujeres con afanes intelectuales) o Quance (se centra específicamente en las mujeres poetas de los años 20 y 30).
} 
todavía en 1927, se anima a enviar poemas suyos a otros países, y sus versos salen a la luz en lugares tan distantes como Lima, Filipinas, Nueva York o Uruguay ${ }^{3}$.

Asimismo quiere saber la opinión que le merecen sus poemas a quien se consideraba sin duda el mejor poeta español del momento, Juan Ramón Jiménez. Le envía su primer poemario en cuanto lo publica, pero no obtiene respuesta. Sin embargo, a los pocos meses coincidió casualmente con él:

Una tarde de otoño en los jardines de la Granja, me encontré de pronto inesperadamente con el Juan Ramón de carne y hueso, acompañado de Zenobia y de algunas otras personas... En seguida me agradeció el envío de mi libro, y en especial el poema dedicado a Platero, y me invitó a visitarle en Madrid (Champourcin 1997, 25-26).

Se conformaría a partir de este momento una relación estrecha entre ambos, que hizo a Ernestina conocer los caminos de la poesía pura y acceder a literatura del ámbito anglosajón que por entonces conocía todavía poco. Además, ser avalada por Juan Ramón Jiménez significaba para ella ser reconocida como poeta sin matices de condescendencia (las revistas con frecuencia aceptaban los poemas enviados por mujeres como una concesión galante ${ }^{4}$ ). Este espaldarazo supuso para Ernestina la voluntad de dedicarse exclusivamente a la poesía.

Por esas mismas fechas, y con una intención similar, otra mujer se dirige a Juan Ramón Jiménez para pedirle consejo sobre su obra. Se trata de Carmen Conde, escritora cartagenera que sentía también una profunda admiración por la obra del maestro. El moguereño le contesta el 4 de julio de 1927:

Me ha sido usted, por sus cartas y poemas, sumamente simpática. Le envío, con el mayor gusto, «Platero y yo»-dedicado hace ya un mes- y estas líneas que me pide usted tan atractiva, tan mimosamente. (Fernández Hernández 90).

Carmen recibe con esta misiva un caluroso impulso, y sus ilusiones literarias quedan reforzadas cuando a los pocos meses Juan Ramón le confirma que publicará sus poemas en Ley, revista que edita para dar a conocer a jóvenes escritores de talento. Una vez impreso el primer número, el poeta le muestra a Ernestina los poemas de Carmen. Champourcin, animada por la admiración con la que Juan Ramón habla de ella, se decide a escribirle. Ya desde su primera carta, el 20 de diciembre de 1927, Ernestina manifiesta tanto su ilusión por escribir como su deseo de encontrar eco en Carmen:

Mi lejana amiga:

Con verdadero placer inicio esta correspondencia, reiterándole mi viva simpatía y el deseo que estas cartas nos hagan intimar un poquito, ya que tácitamente estamos unidas por comunes admiraciones e ideales (Champourcin, Conde 58).

${ }^{3}$ Ernestina guardaba en su archivo personal (que se conserva ahora en el Fondo Ernestina de Champourcin del Archivo General de la Universidad de Navarra, en adelante FECH-AGUN) recortes de estas publicaciones, muchas veces sin preocuparse de marcar la referencia de las revistas de las que procedían. Todos los lugares nombrados aparecen al pie de los recortes, pero solamente en dos casos hay referencia al nombre de la publicación: Manila Bulletin (Filipinas) y Plus Ultra (Nueva York).

${ }^{4}$ Con esta misma expresión, aunque matizada, justificó Valbuena Prat la inclusión de mujeres en su Historia de la literatura española de 1937: «la galantería -y la justicia- obligan a este apartado para las poetisas» (Miró 17).

${ }^{5}$ Todas las citas de cartas de estas autoras en las que no se especifique otra cosa están tomadas de este libro. 
Podemos sospechar que la contestación de Carmen cumplió plenamente sus expectativas:

Querida amiga:

... Preparo un libro (mi libro $1 .^{\circ}$ de poemas en prosa como los que V. conoce. Mis propósitos literarios son estos: escribir, escribir mejor, escribir muchísimo mejor.

... Cuénteme muchas cosas suyas. ¿Sabe V. que tengo una alegría muy grande de tener una amiga tan inteligente? De España, es V. la única muchacha que trato. ¿Hay muchas mujeres de talento, moderno, en Madrid? ¿Va V. al Lyceum Club Femenino? (59)

La gradación con la que comienza Carmen a hablar de su poesía, en su propio ritmo, refleja una voluntad de perfección incompatible con una visión de la escritura como entretenimiento o simple ocupación secundaria. A continuación, aparecen tres características que serán fundamentales en la identidad grupal de las mujeres poetas del 27: la preocupación por temas intelectuales, la convicción de que es necesario estar en la vanguardia de la modernidad y la necesidad de compartir espacios comunes con otras mujeres, de modo que esa identidad catalice en un eco real en la sociedad. Este tercer punto era muy difícil de conseguir para Carmen viviendo en provincias, y Ernestina se apresta a subsanarlo comprometiéndose, de hecho, a hacerle partícipe de todo aquello que suceda en Madrid: es el comienzo de una correspondencia entre ambas escritoras que fue constante entre 1928 y $1932^{6}$.

El lugar por excelencia de reunión de las mujeres interesadas por la poesía en el Madrid de finales de los años 20 era, como nombra Carmen Conde, el Lyceum Club. Esta asociación contaba con un local en el que por primera vez las mujeres podían reunirse para hablar, tomar café, asistir a conferencias, consultar una biblioteca... actividades todas ellas que hasta ese momento estaban confinadas al ámbito privado de las casas particulares. El Lyceum supuso un impulso decisivo para el desarrollo de una conciencia colectiva femenina con una identidad cultural fuerte. Algunas de las mujeres que participaban en sus actividades estaban casadas con intelectuales, y en algunos casos trabajaban estrechamente con ellos (son especialmente conocidos los casos de Zenobia Camprubí y María Lejárraga). Otras, buscaban a través de esta institución formarse y conseguir el impulso suficiente para abrirse un lugar en el mundo de la cultura. Ese era el caso de Ernestina de Champourcin y fue también fue el de Concha Méndez, que muy pronto comenzó a trabajar en la sección de Literatura.

Concha no pertenecía al mundo de la aristocracia. Su conocimiento de idiomas y sus estudios eran privilegio de una familia con dinero pero sin formación cultural, que veía con miedo el fuerte carácter y las serias inquietudes intelectuales de la joven (Nieva 2009, 111-112). Su interés por el mundo literario llegó a través de su novio, Luis Buñuel.

El que con el tiempo acabó siendo un reconocido director de cine vanguardista, era entonces un joven inquieto, amigo de Federico García Lorca, Alberti, Moreno Villa y Dalí, a los que conoció en la Residencia de Estudiantes. Buñuel, arriesgado en sus ideas artísticas, en su vida privada tenía un concepto muy tradicional de la mujer (Ulacia

\footnotetext{
${ }^{6}$ Se conservan prácticamente la mayoría de las cartas que Ernestina envió a Carmen Conde durante este período. Ernestina, sin embargo, perdió las que Carmen le había enviado al tener que marchar precipitadamente de España hacia el exilio mexicano.
} 
1993). Aunque hablaba a Concha con entusiasmo de sus amigos y de los conferenciantes que llegaban a la Residencia, en sus seis años de noviazgo no quiso presentarle a ninguno de ellos. En 1925 terminó su relación con Concha, quien se las ingenió para contactar con Federico García Lorca, ya que Luis le había hablado con especial entusiasmo de él. Federico la invitó a un recital que él mismo daba en el Retiro y ella cuenta que «fue esa noche, al volver a casa, cuando, en silencio, por la alegría, escribí mis primeros poemas» (Ulacia 1990, 46). Se los enseñó a sus nuevos amigos y tanto Lorca como Alberti, a quien conoció en ese mismo recital, la animaron a seguir escribiendo.

Por tanto, a pesar de las primeras dificultades, Concha Méndez pronto cuenta con un primer reconocimiento que la impulsa a adentrarse en el camino de la poesía. Este primer paso es valioso pero insuficiente, no hay que olvidar que Lorca y Alberti eran entonces jóvenes que también estaban luchando por hacerse un nombre en el mundo de la literatura. Concha, además, debía enfrentarse a su ambiente más cercano: le pesan mucho las restricciones que su familia le imponía y considera que para poder desarrollar sus inquietudes necesitaba viajar. Tan claro tiene su objetivo que en una de sus cartas a García Lorca, en agosto de 1925, presenta su escapada como una realidad inminente:

Ya no me contestes aquí a San Sebastián. Marcho pronto, muy pronto. Quizá cuando recibas esta carta, no esté ya aquí. Te escribiré a lo largo de mi viaje y después, cuando esté allí tan sola, entre aquellos hielos, iqué país de melancolía debe ser Suecia! (Ulacia 1993, 14).

El fragmento, aunque breve, muestra la voluntad de Concha de afirmarse como poeta. No pudo entonces realizar ese viaje que le ilusionaba pero sí consiguió publicar su primer libro, Inquietudes (1926). En estos momentos, la vocación poética de Concha era fuerte pero menos definida que la de Ernestina o Carmen Conde; su ilusión era llegar a lo más moderno de la vanguardia y su mayor aspiración era ser directora de cine. Lo que compartían las tres era la ilusión por escribir y la firme decisión de hacerse un nombre en el mundo intelectual para acabar con los prejuicios que relegaban las aportaciones de mujeres a los las páginas femeninas de las revistas.

Tanto Concha como Ernestina publicaron su segundo libro en 1928 (con el título de Surtidor y Ahora respectivamente). La simple continuidad de su escritura era ya un manifiesto, una demostración de su voluntad de seguir adelante en su empeño. Mientras tanto, ambas continúan trabajando juntas en la sección de literatura del Lyceum. En mayo de 1928 prepara un recital de poesía femenina. En la crónica que Ernestina le hace a Carmen por carta de este acto se puede apreciar la conciencia de grupo que en esos pocos meses se ha desarrollado entre las mujeres escritoras de los años 20:

El viernes o sábado tendrá lugar el «torneo poético femenino» en el Lyceum. Toman parte en él Santa Teresa, sor Juana Inés de la Cruz, Gertrudis Avellaneda, Carolina Coronado, en fin, todas las precursoras y luego... nosotras; es decir, Concha Méndez Cuesta, Rosa Chacel, Josefina de la Torre, Isabel Buendía, Pilar Valderrama, tú y yo. Te daré toda clase de detalles transmitiéndote los aplausos que recibirás sin duda... allí mismo se pondrán a la venta los libros de las que los tengan publicados. (81)

Ese «nosotras» es una clara marca de identidad que engloba dentro de sí a las mujeres que se sentían parte de lo que hoy con frecuencia se denomina Generación del 27. Con esta palabra Ernestina implica a Carmen y a las demás que nombra, trasciende su 
propia subjetividad para crear una colectividad. De este modo, reformula y reconstruye una identidad social, común a todas las mujeres poetas. Se percibe en este torneo poético, y en su narración, una conciencia de que para llegar a ser reconocidas como poetas no bastaba con un éxito individual. Era necesaria también una identidad relacional, social, que abriera las puertas a todas las mujeres que a partir de ese momento quisieran seguir caminos intelectuales. Esta identidad colectiva se basaba por tanto en los dos factores básicos que significaban su nexo de unión: la poesía y la condición femenina. Así pues, en este sencillo pronombre se puede reconocer esa solidaridad colectiva que, como señala Stanford Friedman, es necesaria para que las mujeres den un giro al estatismo cultural:

women can move beyond alienation through a collective solidarity with other women -that is, a recognition that women as a group can develop an alternative way of seeing themselves by constituting a group identity based on their historical experience. (40)7 .

En la explicación de quiénes son las mujeres que forman parte de ese «nosotras», además de las poetas citadas hasta este momento aparecen otras dos, Rosa Chacel y Josefina de la Torre. Rosa Chacel, aunque en los años anteriores a la guerra comenzó escribiendo versos, se dedicó pronto casi en exclusiva al ensayo y a la novela. Por sus inquietudes podía sentirse cercana a las poetas de las que vengo hablando, pero no quiso tener relación con el grupo poético que se estaba formando alrededor del Lyceum ${ }^{8}$. Por eso, aunque aparezca en ocasiones citada por estas poetas como escritora moderna, y por tanto como sujeto que suma su valor propio a esta identidad colectiva, no formó parte de la relación de amistad que hubo entre ellas.

En el caso de Josefina de la Torre, fue la lejanía física (vivía en Las Palmas de Gran Canaria) la que le impidió involucrarse de manera activa en el grupo de mujeres escritoras. Josefina había entrado en el mundo de la poesía a través de su hermano Claudio, quien la invitaba con cierta frecuencia a Madrid y le presentó a muchos poetas modernos, tanto de la línea de la poesía pura como vanguardistas. En estos viajes también conoció a Ernestina de Champourcin y Concha Méndez, pero su correspondencia con ellas no fue tan intensa como la que ambas tuvieron, por ejemplo, con Carmen Conde. Josefina de la Torre escribió antes de la guerra dos libros, Versos y estampas (1927), con prólogo de Salinas, y Poemas en la isla (1930), que hacían de ella una prometedora figura en el campo de nuestras letras?.

\footnotetext{
${ }^{7}$ Esta reflexión está basada en un estudio comparativo de autobiografías femeninas en las que la crítica advierte (por contraste con las masculinas) una fuerza particular de la dimensión relacional. También en los testimonios que aquí se recogen queda de manifiesto el interés por subrayar los hechos y pensamientos que conforman la construcción histórica y profesional de las autoras. Y del mismo modo en ellos el aspecto relacional se convierte en determinante.

${ }^{8}$ En marzo de 1928 Ernestina le comenta a Carmen: «Rosa Chacel sigue siendo un misterio. El club femenino la invitó a sus conferencias y ni siquiera contesta. Dicen que es anti-feminista y enemiga del 'Lyceum' lo que no va muy bien con su estilo literario, bastante avanzado» (67-68). Tras la guerra escribió novelas y sólo hacia los últimos años de su vida publicó otro poemario, Versos prohibidos (1978) y una antología Poesía (1931-1991) (1992).

${ }^{9}$ En los años 40 escribió algunas novelas comerciales con el nombre de Laura de Cominges, pero su principal profesión fue la de actriz de cine y teatral. Tras un largo lapso de tiempo publicó otros dos libros de versos, Marzo incompleto (1969) y Medida del tiempo (1989).
} 
Todo el esfuerzo que estas escritoras invirtieron en formarse como poetas y apoyarse unas a otras pronto tuvo una importante vertiente activa que trascendió el campo de la creación para invadir el de la crítica. Así sucede de manera especial con Ernestina de Champourcin. La necesidad de conseguir dinero para publicar, por un lado, y el afán de demostrar su conocimiento de la poesía moderna, por otro, le llevaron a reseñar libros de teoría literaria y comentar los versos de sus coetáneos. $\mathrm{Su}$ reconocimiento en este ámbito llegó especialmente tras la publicación de sus «Escaparates de poesía de hoy», una serie de tres artículos que escribió en 1928 para el prestigioso periódico La Época. En la primera entrega incluyó a Salinas, Guillén y García Lorca junto al reconocido Juan Ramón Jiménez. De este modo, otorgaba a los tres jóvenes un prestigio que no habían tenido hasta entonces a los ojos del gran público. El eco de esta reseña fue grande; tanto que Guillén le pidió a Ernestina que escribiera otro «escaparate» añadiendo a otros autores que él consideraba de gran valía (Champourcin, Conde 238).

En efecto, lo hizo. Pero no sólo para complacer a Guillén, sino porque el éxito del primer artículo le permitía incluir en el segundo, en condiciones de igualdad, a Carmen Conde y Concha Méndez. De este modo, proclamaba en el escenario más preciado de los años 20, el de las revistas literarias, la existencia de un grupo literario en el que, por primera vez, hombres y mujeres compartían el mismo estatus intelectual.

A través de estos «escaparates» Ernestina consiguió labrarse un prestigio como crítica literaria. De ahí que en junio de 1928 reciba una invitación de César Arconada, secretario de La Gaceta Literaria, para participar en una entrevista. Ernestina le explica a Carmen: «me han pedido una entrevista para La Gaceta. Arconada me enviaría aquí las preguntas y a mi vuelta vendrá a hablar conmigo. Seré la primera de una serie que titula 'El secreto de los poetas'» (118). La entrevista se publicó el 15 de julio de 1928. Joy Landeira comenta con gracia la reacción celosa de García Lorca al enterarse de la deferencia que tuvo La Gaceta Literaria hacia la joven Ernestina:

El aparecer en La Gaceta Literaria no era poca cosa. Federico García Lorca, poeta ya bien conocido, sí reaccionó con un poco de celos reales o fingidos a la atención periodística que recibieron Champourcin y Mallo en una carta al periodista Melchor Fernández Almagro: «Creo que ya tú no me estimas. ¡Quién fuera Melgarejo! ¿Quién fuera Ernestina! ¡Quién fuera Maruja Mallo!»(105-6)

Para alcanzar en el espacio público el reconocimiento que ellas perseguían, era necesario dar un paso más, que los críticos reseñaran, analizándolos y no simplemente dando noticia de ellos, los libros que ellas escribían. Ernestina sabe que sólo entonces podrán ser reconocidas como poetas. En un primer momento habían centrado todo su empeño en publicar, que para ellas significaba un esfuerzo añadido: sus poemarios, por ser de mujer, parecían dirigidos a un público aún más reducido que el de la poesía en general, ya estrecho de por sí. Sin embargo, tanto Concha como Ernestina consiguen publicar su segunda obra, como hemos visto, en 1928. Mucho más difícil fue para Carmen que Brocal viera la luz, pero la Imprenta de la Ciudad Lineal acabó editándolo a mediados de 1929. Cuando estas obras empiezan a circular, lo decisivo es su difusión y que encuentren eco en las revistas literarias, que los críticos sepan apreciar su calidad y sus horizontes. Por eso, Ernestina le insiste a Carmen: 
Probablemente mañana quedará mi libro en la imprenta. ¿Qué sabes del tuyo? Me encantaría que salieran juntos. Supongo que tendrás una lista de críticos a quienes pueda interesar para enviarles ejemplares. Si quieres yo te daré nombres y señas de algunos amigos míos que seguramente se ocuparán con gusto de Brocal. (68)

Y de hecho, en cuanto su amiga le comunica que acaba de recibir el libro, el 7 de julio del 29, concreta todavía más:

Si mandas el libro a 15 críticos ya está bien. No olvides a Canedo ni al Poeta. Obregón y Salazar lo esperan para echar al aire «sus campanas y sus palmas».

Ahora piensa en el segundo. Sería bueno lanzarlo pronto y mejor que éste. ¿Por qué no intentas con Litoral o la Iberoamericana? (306)

Se conservan varias reseñas de Ahora en revistas y periódicos como La Gaceta Literaria, El Sol, ABC, La Voz del Cantábrico, incluso en Avance, revista de vanguardia que se publicaba en La Habana (en FECH-AGUN). Sin embargo, la difusión de Brocal fue más problemática. Antonio Oliver, aunque no impedía a su novia que escribiera, estaba inmerso en los prejuicios de su época, que no consideraban pertinente que una mujer mantuviera una correspondencia de tipo profesional. Así se lo cuenta Carmen a Ernestina, comentándole que accederá a lo que su novio le pide. Sin embargo, Ernestina le contesta con una larga y enérgica carta en la que le recuerda que dar a conocer su libro es imprescindible si quiere verdaderamente llegar a ser poeta. Por tanto, que el asunto es suficientemente grave como para no ceder:

Queridísima mía, comprendo todas tus penas y tu tristeza. Si supieses qué cerca me tenías mientras leía tus líneas. Vente pronto. Escápate de esa horrible prohibición. Pero no te dejes sujetar aunque sea por el amor. Compréndelo. Es absurdo que te doblegues a esas ridículas exigencias de novio burgués. Perdóname, pero estoy indignada. Si tu novio te quiere de veras no puede ni debe entorpecer así tu camino. Si cedes así ahora, ¿qué será luego? Perderás lentamente toda tu personalidad.

Del éxito de tu libro dependen otros escritos futuros. Créeme, en esto debes imponerte, aunque te cueste un pequeño disgusto.

En último caso mándame los libros firmados y yo me encargo de distribuirlos. Nadie tiene derecho a impedir que conquistes el puesto que te corresponde.

Mantente fuerte y optimista. En tus manos está el llegar. No vuelvas a tu desánimo del año último. No rompas tus confidencias, las llevo muy dentro, muy cerca de lo mejor mío.

Adaptarse es morir. Tu tienes valor suficiente para vivir y luchar. Contra todos se siente uno más fuerte, más temerario.

Te quiero mucho, mucho y te abrazo cerca, en tu pena...

YO (312-313)

La fuerza de la carta y la claridad de sus ideas son muy importantes. En un contexto de sospecha constante hacia lo que querían hacer, el consejo y el ánimo de una amiga empeñada en la misma tarea resultaba decisivo. Para Ernestina, poder hablar con Carmen supone en muchas ocasiones un desahogo necesario y una fuerza de la que sacar impulso. A su vez, por la sencilla ascendencia que le dan sus pocos años de más y el tener 
publicados ya dos libros, pone todo su empeño, tanto en esta como en numerosas otras cartas, en no permitir que Carmen decaiga en su ilusión de escribir ${ }^{10}$.

En el diálogo que establecen estas dos escritoras, Concha Méndez ocupa un papel relevante. Por estar por encima de las convenciones y por su carácter indómito, se atreve a dar pasos radicales que ambas admiran sin atreverse a imitar. Esta es la razón por la que, al hablar de ella, se refieren principalmente a su vida y sus actividades, más que a su producción poética. Además, al poco de publicar Surtidor, Concha empieza a orientar sus intereses hacia el teatro y el cine. Ya en mayo de 1928 está haciendo planes para viajar a la capital de la industria cinematográfica. Ernestina le cuenta a Carmen: «[Concha] se dispone a marchar el invierno que viene a 'Los Ángeles'. Va a aprender dirección cinematográfica» (87). Carmen le pide, asombrada, que le siga contando «esas extraordinarias cosas de las chicas que tratas» (89). Ernestina le responde trasladándole la visión que la sociedad tiene de una mujer que se empeña en formar parte de la sociedad intelectual: «Concha Méndez... hace vida de escritor-hombre. Va a tertulias, cafés, etc. Yo no la censuro, pero encuentro el ambiente de 'café', feo, antiestético. Pero aquí las reuniones artísticas no se conciben en otra parte». (195). Ni siquiera Ernestina, en su lucha por el reconocimiento público de las mujeres poetas, era capaz de entrar en determinados cenáculos de la sociedad literaria. Sin embargo, Concha no tenía inconveniente en participar de cualquier actividad que le pareciera de interés.

Esta actitud, y el hecho de que efectivamente siguiera publicando libros de poemas, hace que las tres consideren que forman parte de un mismo núcleo. Ernestina, en su interés por mantener vivos los lazos que las unen, habla con frecuencia a Concha de Carmen y viceversa:

Concha tiene ganas de conocerte, siente por ti una gran simpatía aunque sois, a mi juicio, completamente opuestas. Ella hace versos como juega al tennis o gana campeonatos de natación. Su familia le ha prohibido escribir y en vista de eso quiere marcharse fuera, se irá a Londres probablemente. (247)

En estas cartas se trasluce una y otra vez el contraste entre las inquietudes de las jóvenes y la cultura dominante, que insiste en que la escritura no es una profesión de mujer. Esta oposición constante se le hace a Concha tan dura que, como anuncia Ernestina, acaba por escaparse, con gran escándalo de muchas de sus amistades (Champourcin, Conde 266-7). Aunque sus ilusiones estaban puestas en América, en esas condiciones el desplazamiento le resulta demasiado largo y costoso. Al final decide hacer un viaje más cercano, a Londres.

Al llegar allí, busca en primer lugar un modo de subsistir, empleándose en una oficina y dando lecciones de español. Pero en cuanto tiene un momento libre lo emplea a fondo en su interés principal: se acerca a los estudios cinematográficos para tratar de encontrar un hueco en ellos. Mientras tanto, se esfuerza también por dar a conocer en Londres todo lo que las mujeres están comenzando a hacer en España. En una carta de mayo de 1929 le dice a Ernestina:

${ }^{10}$ A pesar de los obstáculos, Carmen Conde conservaba en su archivo personal varias reseñas de esta primera obra. Abundan las publicadas en revistas y periódicos locales, como Sudeste, La Verdad o El Liberal, pero hay también críticas en La Época, El Sol, Cosmópolis (Madrid) y Avance (Cuba). 
Por Pilar sé que el Lyceum va marchando. Debéis sostenerlo a costa de lo que sea. Viendo la cantidad de Clubs femeninos que hay aquí en Londres no puede menos que desearse que en España se pongan las cosas a otro nivel que están, empezando por esto de tener un Club las mujeres que es en los tiempos modernos algo bastante necesario. Yo, si desde aquí puedo serviros, podéis contar conmigo como siempre...

Sigo creyendo, más cada vez, que esto de viajar es algo necesario para los que aspiramos a hacer algo en la vida. Primero hay que vivir, vivir, VIVIR. Después, con la experiencia, crear, crear, CREAR. Y mientras tanto trabajo, y estudio y tenacidad y confianza, y optimismo.

... En estos días daré el recital de poesía moderna y naturalmente leeré tus poemas.

Y para el mes próximo tengo la conferencia. (FECH-AGUN)

El interés de Concha por promocionar a sus amistades y darles un eco internacional es claro. Se esfuerza por conseguir versos actuales de todos los poetas jóvenes y modernos, citando a hombres y mujeres sin distinción. Pocas semanas después de enviar esta carta vuelve a España, y casi antes de llegar comienza a preparar su siguiente viaje, esta vez a Buenos Aires. Le atrae América y especialmente la atmósfera literaria que se respira en la capital argentina. Allí se pone en contacto con escritoras que ya habían conseguido alcanzar un prestigio internacional, como Alfonsina Storni, Juana de Ibarbourou, Consuelo Berges... Al igual que había hecho en Londres, se hace portavoz de la vanguardia madrileña. La facilidad de encontrarse en un país con el que compartía la lengua le permitió colaborar en la prensa argentina y dar conferencias en las que se refirió, de manera específica, al joven movimiento femenino en la poesía:

En cuanto a la mujer en España, puedo decirles que ha despertado, y de un modo brillante, a una vida activa, tanto en el orden social como en el intelectual. Y así, ha invadido universidades y ha creado algún centro. Actualmente, contamos con un grupo de jóvenes poetas y escritoras como Rosa Chacel, Ernestina de Champourcin, Carmen Conde, Josefina de la Torre, etc., que comienzan brillantemente su carrera artística. Por primera vez se da en España un movimiento poético femenino tan vario e intenso. Yo, al venir aquí, traigo el saludo de esta generación para las poetisas y escritoras americanas, y a mi vez, y en particular, mi admiración más profunda. (Valender 46-7)

También Ernestina tiene la oportunidad de enviar a finales de 1929 a Buenos Aires (en concreto a la revista Síntesis), un artículo en el que presenta a las jóvenes escritoras españolas, afirmando que se trata de un grupo en cierto modo consolidado, de poetas que «poseen ya el tono fundamental que caracteriza la poesía femenina del futuro» (Dougherty 658). Si bien es cierta, como afirma Dougherty, la escasa presencia de poetas femeninas en las revistas de vanguardias (654), no lo es menos que esas pocas mujeres que habían conseguido llegar hasta allí habían dado un paso de gigante al conseguir ser juzgadas con los mismos parámetros que sus colegas masculinos. Ernestina en este artículo cita algunas de las características comunes de la obra de estas poetas (su interés por el mundo moderno, una expresión aséptica, su adhesión a las vanguardias) ${ }^{11}$, reforzando la conciencia de grupo,

\footnotetext{
${ }^{11}$ Está por hacer un estudio en profundidad sobre los rasgos poéticos de estas autoras que muestre si las relaciones que establecen entre ellas dejan un rastro marcado en sus obras. Los trabajos que he hecho en otros lugares sobre estas autoras me permiten aventurar que se insertan con voz propia (aunque no siempre segura) en las dos grandes corrientes de su época (poesía pura y vanguardias), y que sin embargo su mutua influencia no llega a alcanzar un peso significativo (ver Fernández Urtasun \& Antón, González-Allende y Díez de Revenga).
} 
aunque el hecho es que con el paso de los años serán fundamentalmente Carmen Conde y ella quienes conseguirán alcanzar una neta voz propia y una obra extendida en el tiempo.

La tensión expresiva y de reconocimiento público que aparece en los testimonios citados hasta aquí empieza a decaer al poco tiempo. Cuando en primavera de 1931 se produjo en España el cambio político que trajo consigo el advenimiento de la República, Concha decidió volver a Madrid. Al poco tiempo conoció a Manolo Altolaguirre, con quien se casó al año siguiente. Aunque Manolo impulsó la obra creativa de Concha, ella optó por dedicarse intensamente a su vida familiar y a los proyectos editoriales de las revistas Héroe y 1616, dejando en un lugar secundario su labor de creación. En diciembre de ese mismo año también Carmen Conde se casó con Antonio Oliver. Juntos pusieron en marcha un interesante proyecto, la Universidad Popular de Cartagena, que absorbió durante un tiempo todas sus fuerzas. Y casi al mismo tiempo, en febrero de 1932, Ernestina de Champourcin conoce a Juan José Domenchina, con quien acabaría casándose en 1936. Estas circunstancias, y el hecho de que se produzcan casi a la vez, hacen que las autoras a partir de este momento se replieguen más sobre su vida íntima y vayan dejando al margen la relación entre sí, su interés por la cultura y su dimensión pública de la mujer, sin que en ningún momento esto signifique dejar de escribir.

De hecho, Concha muestra las vivencias de su nueva vida en dos libros de versos, Vida a vida (1932) y Niño y sombras (1936). Carmen publica Júbilos en 1934 y Ernestina de Champourcin explora los campos de las vanguardias con La voz en el viento (1931) y sobre todo Cántico inútil (1936), un libro que llamó la atención porque la autora no muestra en él una amor restringido a «los límites expectantes receptivos, peculiares de su sexo y habituales de en nuestro clima... [lo que] canta con profundo acento y patética belleza es el amor activo, dadivoso, iluminado» (Torre sp). También en estos años ve la luz el único libro poético de Rosa Chacel, A la orilla de un pozo (1936), con prólogo Juan Ramón Jiménez.

Antes de que comience la guerra civil todavía se produce un hecho que tendrá mucha relevancia en el reconocimiento público de estas poetas. En 1932 publica Gerardo Diego su primera edición de la Poesía española contemporánea. El éxito de la antología, junto con las críticas y sugerencias recibidas, le anima a publicar una segunda y definitiva edición en 1934, considerada hoy por la crítica como el canon oficial de la generación del 27. En ella aparecían dos mujeres, Ernestina de Champourcin y Josefina de la Torre. Por primera vez se las citaba en igualdad de condiciones con el resto de los que ellas consideraban sus compañeros.

Como he comentado al principio, la guerra civil supuso una ruptura definitiva en la continuidad de estas escritoras como grupo. Josefina de la Torre dejó su camino poético para dedicarse a trabajar como actriz. Concha Méndez se exilió, primero a Cuba y después a México, donde trató de buscar una continuidad con su vida anterior a través de la poesía $^{12}$. Ernestina de Champourcin también en el exilio intentó recomenzar el itinerario truncado. Por un lado, consciente de la importancia del apoyo mutuo que había experimentado, trató de impulsar la poesía femenina mexicana con revistas como Rueca. Por otro, continúa con la vocación de escritora que la define. Su obra, con algunos momentos de silencio, mantendrá un ritmo constante tanto en el exilio como al volver a Madrid y

\footnotetext{
${ }^{12}$ Sin embargo, tras la separación de su marido en 1944 dejó de escribir definitivamente.
} 
hasta el final de su vida: publica su último poemario, Presencia del pasado, con 91 años. Afincada en Madrid, Carmen Conde sigue, apoyada en su fuerte voluntad, un camino en solitario, en el que no hay confluencia directa de intereses con las poetas que le rodean. Ve cómo otras jóvenes escritoras comienzan ya a escribir en circunstancias muy distintas a las suyas, con una apertura social mucho mayor. Pero su constancia y sus esfuerzos se verán compensados con premios y reconocimientos, como la obtención en 1967 del Premio Nacional de poesía. Sobre todo es significativo, y así suele destacarse, que fuera la primera mujer que pudo entrar a formar parte, en 1979, de la Real Academia Española. En el acto, importante no sólo para Carmen sino para todas las mujeres escritoras e intelectuales que abarrotaban la sala, estaba Ernestina aplaudiendo entre el público. También a ella a partir de su vuelta a España, en 1972, le habían empezado a reconocer con premios y distinciones. En la mayoría de estos homenajes que se tributaron hacia el final de sus vidas a las mujeres poetas del 27 , no solamente se hacía alusión a la calidad alcanzada a lo largo de sus dilatadas obras, sino también se les agradecía que hubieran abierto camino a muchas otras mujeres dentro del mundo intelectual ${ }^{13}$.

\section{OBRAS CITADAS}

AnTón, María Elena (2008): «Diarios y memorias de Ernestina de Champourcin: algunos fragmentos inéditos», Rilce 24.2, p. 239-74.

Cano Ballesta, Juan (2006): «Ernestina de Champourcin y la generación del 27.» Ernestina de Champourcin: mujer y cultura en el siglo XX, Rosa Fernández Urtasun y José Ángel Ascunce eds., Madrid, Biblioteca Nueva, p. 23-36.

Castillo-Martín, Marcia (2001): «Contracorriente. Memorias de escritoras de los años 20.» Espéculo $17<\mathrm{http} / / / \mathrm{www} . \mathrm{ucm} . \mathrm{es} / \mathrm{info} / \mathrm{especulo/numero17/memor \_ 20.html>}$

Champourcin, Ernestina de (1997): La ardilla y la rosa (Juan Ramón en mi memoria), Huelva, Fundación Juan Ramón Jiménez.

Champourcin, Ernestina de, y Carmen Conde (2007): Epistolario (1927-1995). Ed. Rosa Fernández Urtasun ed., Madrid, Castalia.

Díez de Revenga, Francisco Javier, ed. (2007): Carmen Conde. Voluntad creadora, Cartagena, Ayuntamiento de Cartagena.

Dougherty, Dru (2009): «Una poética del zigzagueo: Ernestina de Champourcin (1926-1936).» Hispania 92.4, p. 653-63.

EAKIN, Paul John (1998): «Relational Selves, Relational Lives: The Story of the Story.» True Relations: Essays on Autobiography and the Postmodern. G. Thomas Couser y Joseph Fichtelberg eds., Wesport, Greenwood Press, p. 63-78.

FECH-AGUN. Cartas, reseñas y artículos conservados en el Fondo Ernestina de Champourcin del Archivo General Universidad de Navarra.

Fernández Hernández, Caridad (1998): «Correspondencia del archivo Carmen Conde-Antonio Oliver.»Monteagudo 3, p. 85-100.

\footnotetext{
${ }^{13}$ Estos reconocimientos están favoreciendo también que cambie nuestro modo de entender la historia de la literatura. Como explica Wilcox «the work of Méndez and Champourcin challenges our androcentric view of Spanish poetry of the 1920s» (123). Recientemente, hablando de Ernestina de Champourcin, Cano Ballesta ha reconocido que «logró abrir nuevos horizontes a la poesía,... estaba aportando decisivas innovaciones que contribuían a lo que fue el cambio general de las letras españolas de los años 30» (34-5). Así pues, el conocimiento cada vez más profundo de la poesía femenina de los años 20 está sirviendo para reinterpretar esa época de la literatura española.
} 
Fernández Urtasun, Rosa y María Elena Antón (2005): «Introducción.» Ernestina de Champourcin, Poesia antologia / Antología poética, Vitoria, Diputación Foral de Álava, p. 16-97.

GoNZÁLEZ-AlLENDE, Iker (2010): «Cartografías urbanas y marítimas: género y modernismo en Concha Méndez.» Anales de la literatura española contemporánea, 35.1, p. 89-116.

Hazlett, John Downton (1998): My generation. Collective Autobiography and Identity Politics, Wisconsin, The University of Wisconsin Press.

LANDEIRA, Joy (2005): Ernestina de Champourcin, vida y literatura, Ferrol, Sociedad de Cultura Valle-Inclán.

MAINER, José-Carlos (1990): «Las escritoras del 27 (con María Teresa León al fondo).» Homenaje a María Teresa León, Madrid, Universidad Complutense, 1990, p. 13-39.

Miró, Emilio (1999): Antología de poetisas del 27, Madrid, Castalia.

NiEva DE LA PAZ, Pilar (2009): «Modelos femeninos de ruptura en la literatura de las escritoras españolas del siglo XX», Roles de género y cambio social en la literatura española del siglo $X X$, Pilar Nieva de la Paz ed., Amsterdam-New York, Rodopi, p. 107-131.

- (2006) «Voz autobiográfica e identidad profesional: las escritoras españolas de la Generación del 27», Hispania, 89.1, p 20-26.

QUANCE, Roberta (1998): «Hago versos, señores.» Breve historia feminista de la literatura española (en lengua castellana) vol. 5, Iris M. Zavala ed., Barcelona, Anthropos, p. 185-210.

Quiles FAz, Amparo (2008): «Isabel Oyarzábal Smith: mujer, prensa e ideología», Mujer, literatura y esfera pública: España 1900-1940, Pilar Nieva de la Paz, Sarah Wright, Catherine Davies y Francisca Vilches de Frutos eds., Philadephia, Society of Spanish and Spanish American Studies, p. 61-72.

Stanford Friedman, Susan (1988): «Women's Autobiographical Selves. Theory and practice», The Private Self, Shari Benstock ed., Chapell Hill, The University of North Carolina Press, p. 34-62.

Stanton, Domna C. (1987): «Autogynography: Is the Subject Different?», The Female Autograph: Theory and Practice of Autobiography from the Tenth to the Twentieth Century, Chicago, University of Chicago Press, p. 3-20.

TORRE, Guillermo de (1938): «Dos libros de Ernestina de Champourcin», El sol, n. pag. FECH-AGUN

Ulacia Altolaguirre, Paloma (1993): «Concha Méndez y Luis Buñuel», Ínsula 557, p. 12-5.

- (1990): Concha Méndez: memorias habladas, memorias armadas, Madrid, Mondadori.

VAlender, James (2001): Manuel Altolaguirre y Concha Méndez. Poetas e impresores, Madrid, Residencia de Estudiantes.

Wilcox, John C. (1997): Women Poets of Spain, 1860-1990, toward a Gynocentric Vision, Urbana, University of Illinois Press. 